\title{
BMJ Open What are the perceived influences on asthma self-management at the workplace? A qualitative study
}

\author{
Katherina Heinrichs, ${ }^{1}$ Patricia Vu-Eickmann, ${ }^{1}$ Stefan Hummel, ${ }^{2}$ Jalal Gholami, ${ }^{3}$ \\ Adrian Loerbroks ${ }^{1}$
}

To cite: Heinrichs K, VuEickmann P, Hummel S, et al. What are the perceived influences on asthma selfmanagement at the workplace? A qualitative study. BMJ Open 2018;8:e022126. doi:10.1136/ bmjopen-2018-022126

- Prepublication history and additional material for this paper are available online. To view these files, please visit the journal online (http://dx.doi. org/10.1136/bmjopen-2018022126).

Received 5 February 2018

Revised 3 May 2018

Accepted 12 July 2018

D Check for updates

(c) Author(s) (or their employer(s)) 2018. Re-use permitted under CC BY-NC. No commercial re-use. See rights and permissions. Published by BMJ.

${ }^{1}$ Institute of Occupational, Social, and Environmental Medicine, Centre for Health and Society, Faculty of Medicine, University of Düsseldorf, Düsseldorf, Germany

${ }^{2}$ Department of Pneumology and Allergy, MEDIAN Klinik Heiligendamm, Bad Doberan, Germany

${ }^{3}$ Department of Pneumology, Nordseeklinik Borkum, Borkum, Germany

Correspondence to Dr Adrian Loerbroks; adrian.loerbroks@uniduesseldorf.de

\section{ABSTRACT}

Objectives Asthma can represent a substantial challenge to the affected individual, but is usually well controlled by adequate asthma self-management behaviour (SMB). Asthma SMB comprises symptom prevention, symptom monitoring, acute symptom management and communication with important others. The implementation of asthma SMB seems to depend on contextual factors. For employed adults, working conditions may be important in this respect. We, therefore, aimed to explore the perceived influences on effective asthma SMB at work.

Design Our qualitative study built on semi-structured interviews and qualitative content analysis.

Setting Participants were recruited in two pulmonary rehabilitation clinics in Northern Germany.

Participants We conducted 27 interviews among employees with asthma (female: $n=15$ ) who worked at least 20 hours per week and were diagnosed with asthma at least 6 months prior to interviewing. Patients with chronic obstructive pulmonary disease were excluded. Results According to participants, the most influential factors with regard to asthma SMB at work appeared to be job decision latitude (JDL) and social support. JDL (ie, the control over one's tasks and when and how things were done) was perceived to affect symptom prevention, symptom monitoring, and acute symptom management, but not communication. Support by colleagues, line managers, and the employer, for example, practical, emotional, or structural support, was perceived to exert effects on symptom prevention, acute symptom management, and communication (ie, self-disclosure of one's condition).

Conclusions Perceived JDL and social support were experienced as influencing successful implementation of asthma SMB at the workplace.

Trial registration number German Clinical Trials Register no: DRKS00011309.

\section{INTRODUCTION}

Bronchial asthma is a chronic lung disease which affects approximately 300 million individuals worldwide ${ }^{12}$ and represents a considerable public health challenge. ${ }^{34}$ Asthma can constitute a substantial burden to patients impairing several domains of their quality of life. ${ }^{15} 6$ Possible adverse consequences

\section{Strengths and limitations of this study}

Our participants were recruited in rehabilitation clinics to reduce possible healthy worker effects.

- Participants' asthma diagnosis and the absence of comorbid chronic obstructive pulmonary disease were confirmed by treating physicians.

- The similar professional backgrounds of the analysts might have impaired qualitative data analysis.

- Patients were neither involved in the development of the study design nor involved in data analyses.

in terms of individuals' working lives are increased sick leave, reduced workability and early retirement. ${ }^{78}$

The impact of asthma on patients' lives is less pronounced when the condition is well controlled. ${ }^{1}$ An effective means to increase asthma control and to improve patients' prognosis is appropriate asthma self-management behaviour (SMB). ${ }^{9}$ Asthma SMB encompasses a wide range of activities which relate to trigger avoidance (eg, of allergens, such as pollens, or of non-allergic triggers, such as smells), symptom monitoring, strategies to acute symptom management (eg, breathing techniques) ${ }^{2}$ and communication with important others, which includes self-disclosure of the illness. ${ }^{10}$

The implementation of effective asthma SMB is assumed to depend on contextual factors, such as the extent of received social support or one's opportunities for workplace modifications or alternative work arrangements. ${ }^{10} 11$ As these examples illustrate, working conditions may be of special importance for SMB of asthma among adults. A recent systematic review, conducted by our research group, suggested that quantitative research on this topic mostly addressed very specific variables (eg, self-disclosure at work being the only SMB) and produced only piecemeal insights or no asthma-specific evidence. ${ }^{12}$ Qualitative approaches allow for a better understanding of 
the matter because of their open, flexible and interactive approach to data collection. To our knowledge, two qualitative studies have to date addressed asthma SMB in the workplace context. The first study, by Boot $e t a l,{ }^{13}$ described different adaptation profiles among employees with asthma or chronic obstructive pulmonary disease (COPD). The authors referred to possible interactions between working conditions and asthma SMB-for example, a lack of staff replacement in case of sick leave related to a reluctance to take sick leave-but concrete examples were hardly presented. ${ }^{12}$ Another qualitative study, by Zhao et $a l,{ }^{11}$ explored asthma at the workplace based on a triangulation of perspectives of human resource personnel as well as employees with and without asthma. Among others, the authors reported that employees with asthma felt reluctant to disclose their condition to their employer, because they were concerned that others may consider them professionally incompetent or that they might ultimately lose their jobs. ${ }^{11}$ Moreover, the authors highlighted the role of privacy at work as influential on medication use at work and emphasised the role of support as a determinant of acute symptom management and self-disclosure. ${ }^{11}$

Our aim was to provide additional in-depth exploration of the perceived occupational influences of asthma SMB at work based on a qualitative inquiry. Except for possibly novel insights, our study will make at least one important methodological contribution: it is well known in occupational health research that observations can be biased by the so-called healthy worker effect (HWE). ${ }^{14}$ The HWE, which has also been confirmed for employees with asthma, ${ }^{14}$ implies that apparently healthy individuals are more likely to obtain and remain in employment than individuals in poor health (for an overview, see reference ${ }^{15}$ ). In fact, the HWE might be particularly pronounced in asthma research since specific environmental exposures at work can cause or trigger asthma. ${ }^{14} 15$ As a result, asthma might be related to reduced workability, increased sick leave and unemployment. ${ }^{1617}$ Thus, those individuals with asthma who may experience significant difficulties related to asthma SMB at work might not be included in studies which sample individuals in active employment. Hence, such samples might predominantly comprise cases of mild and moderate asthma. It remains uncertain as to what extent the samples included in prior studies are affected by the HWE. ${ }^{113}$ We attempted to minimise potential selection bias due to the HWE by recruiting participants in rehabilitation clinics. Those samples are likely to include employees with asthma who are at risk of quitting or losing their jobs. In Germany, individuals in inpatient rehabilitation are by definition unable to work, a status similar to having a sick note. Thus, our participants were not actually working at the time of interviewing in the clinics, though they were contractually employed. Additionally, owing to our recruiting in rehabilitation clinics, we were able to make use of the patients' admission records to verify asthma diagnoses instead of relying on self-report information only, as earlier studies did. $^{11}$
In summary, in the present study, we aimed to improve our understanding of the working conditions that may influence asthma SMB at work by interviewing employees with asthma who were or had until recently been in pulmonary inpatient rehabilitation.

\section{METHODS}

\section{Study participants}

In Germany, inpatient or outpatient medical rehabilitation is supposed to assist individuals with severe illnesses to maintain or regain workability. This implies that to be considered for rehabilitation, one's workability needs to be at stake or is already impaired by one's illness. Usually, pulmonary rehabilitation spans across a period of 3 weeks with the option to extend this period to a total of 4 weeks. Once medical rehabilitation is completed, patients generally need to wait for at least 4 years before they are eligible to receive another such treatment. Rehabilitation services are, in most cases, financed by the health insurance carrier or the German Pension Fund. We recruited participants in two inpatient rehabilitation clinics in Northern Germany (MEDIAN Klinik Heiligendamm and Nordseeklinik Borkum). Inpatients were eligible for participation in case all of the following criteria were met:

- a diagnosis of and current treatment of asthma, but not COPD, which is easily diagnostically confused with asthma. ${ }^{18}$ These criteria were determined by the treating physician at the respective clinic based on available records and were confirmed by self-reports of physician diagnoses from participants;

- employment of at least 20 working hours per week in the last 6 months;

- having worked with the diagnosis for at least 6 months.

The latter two criteria were applied to reduce the potential recall bias and to ensure that the employees had experienced a reasonable period of time working with asthma.

\section{Qualitative interviews}

To explore the working conditions potentially shaping asthma SMB at work from the affected individuals' point of view, we decided to carry out qualitative semi-structured interviews supported by a topic guide. Based on prior research of our study team, ${ }^{19}$ the topic guide was drafted by the study coordinator (KH) and then expanded, refined and conceptually linked to prior work ${ }^{10}$ (see below). Members of the study team (AL, KH and PV-E) reviewed and discussed the topic guide until it took its final form (see table A in the online supplementary material). Broad introductory questions about the usual daily work tasks (example: "How do you experience a typical day at work?") were followed by questions about asthma symptoms and SMB in general (example: "What do you have to do in your everyday life, not only at work, to deal with your asthma?"). Open-ended questions on SMB drew on the conceptualisation by Mammen and Rhee, ${ }^{10}$ who suggested four domains of asthma SMB: symptom prevention, symptom monitoring, acute symptom 
management, and communication with important others (example: "How do you prevent asthma exacerbations in your everyday life?"). Next, and most importantly, we explored as to what extent and how perceived work-related factors may subjectively promote or impair the implementation of asthma SMB at work (example: "What factors do help you to manage your condition at work?"). Finally, we asked the study participants to elaborate on possible interventions that may support them in implementing SMBs at work (example: "What measures would help you to manage your asthma (even) better at your workplace?"). At the end of the interview, the study participants were given the opportunity to add anything that had not yet been mentioned.

Potential study participants were approached by their treating physician at the rehabilitation clinic or by the study coordinator who spent a week at each clinic. Information on the study was given orally as well as in writing, and it was ensured that the participation in the study was voluntary. In case individuals agreed to participate, an appointment for an interview was scheduled. If potential participants were unsure, they were approached again, mostly on the next day. Prior to the qualitative interviews, all participants provided written informed consent and completed a brief questionnaire collecting sociodemographic, occupational and medical data. The qualitative interviews were conducted between January and April 2017, mostly face-to-face at the rehabilitation clinics. Seven interviews were led by telephone, mostly because the respective patients were approached on their last day(s) at the clinic, which are usually busy. The telephone interviews were conducted latest within 4 weeks after discharge from the clinic. All interviews were digitally recorded and transcribed. All interviews were conducted by the study coordinator (KH) to improve reliability. KH holds master degrees in psychology and public health and had prior experience in conducting interviews with chronically ill individuals. Data were collected until thematic saturation was achieved. Our study received ethical approval from the Institutional Review Board of the Medical Faculty of the Heinrich-Heine University of Düsseldorf (no 5764R).

\section{Data analyses}

Qualitative content analysis ${ }^{20}$ was conducted in an iterative process by three members of the interdisciplinary study team using the qualitative data analysis software MAXQDA. In a first step, a set of codes based on the topic guide was defined by the study coordinator KH (deductive coding), which had been developed according to the asthma SMB domains by Mammen and Rhee. ${ }^{10}$ In the second step, the code system was refined based on the interview material (inductive coding), which means that subcategories were developed and further subdivided, so that several levels of main and subcategories resulted from the process. For five interviews, this was done independently by two different members of the study team (KH and PV-E). Then, the two developed code systems were discussed and merged after reaching consensus. The final set of codes (developed by $\mathrm{KH}$ ) was reviewed by AL and PV-E, which resulted in minor modifications of the code structure. According to the method of content structuring, ${ }^{20}$ we summarised the content of several statements within one category and of several subcategories within one (main) category. In total, the study team conducted three coding rounds.

To gain an understanding of different occupational contexts and thus working conditions, we aimed at collecting data among different professional groups. Therefore, as mentioned above, we asked participants not only to state their job title but also to describe their daily tasks and working routines. Those job descriptions were categorised by the study team into mainly physical demands (eg, construction work), cognitive/social demands (eg, white-collar jobs) or mixed demands (eg, healthcare). In case of discrepancy, decisions were discussed until consensus was achieved.

\section{Patient involvement}

Patients were neither involved in the designing of our study nor involved in data analyses. The results were disseminated to all patients who agreed to receive such information.

\section{RESULTS}

In total, 27 qualitative interviews were conducted and entered content analysis. One person did not return the background questionnaire. Participants were aged between 41 and 62 years, and more than half were women $(n=15)$. Most participants worked full time. Table 1 depicts further characteristics of our sample which was fairly heterogeneous, for example, concerning school degrees or job-related demands. The following examples for jobs with cognitive or psychosocial demands emerged: secretary, interpreter or kindergarten manager. Jobs with primarily physical demands included order picker, stockman or mail carrier. Examples of mixed exposures at work are nurse, medical-technical assistant or salesclerk.

The duration of interviews ranged between 20 and $54 \mathrm{~min}$ with an average duration of $34 \mathrm{~min}$. Described

\begin{tabular}{|c|c|}
\hline Variable & \\
\hline Age in years, mean (SD) & $52.5(5.6)$ \\
\hline Sex: female; $n, \%$ & $15,57.7$ \\
\hline Secondary school degree or higher; $n, \%$ & $18,69.2$ \\
\hline Full-time employment; n, \% & $21,80.8$ \\
\hline Job demands mainly cognitive/psychosocial; n, \%* & $17,65.4$ \\
\hline Job demands mainly physical; n, \%* & $4,15.4$ \\
\hline Job demands mixed; $n, \%^{*}$ & $6,23.1$ \\
\hline Obesity (body mass index $\geq 30$ ); $n, \%$ & $16,61.5$ \\
\hline Ever smoker; $n, \%$ & $19,73.1$ \\
\hline
\end{tabular}

*Variable constructed based on interview contents. 
behaviours were only coded as asthma SMB if participants reported that they had actually carried out those behaviours at work (in contrast, eg, to SMBs that participants wished to newly implement on their future return to work). Quotes from the transcriptions can be found in table $\mathrm{B}$ in the online appendix.

\section{Symptom prevention: trigger avoidance}

Asthma-specific SMB implemented at work mainly referred to trigger avoidance, in particular to the avoidance of odours (quote 1, online supplementary table B), job-related physical activity (quotes 2,3 ), house dust (quote 4), and pollens (quote 5).

Quote 3: I have to work with files. At times, when I do not feel well, the colleagues are really very friendly and bring and fetch the files, so that I do not need to carry them myself. So there is notable consideration.

Factors described as contributive to effective trigger avoidance showed great variety. First, the mere absence of triggers was perceived as beneficial (quote 4). Further, some participants stated that their colleagues helped them avoid their relevant triggers, for example, in case of exercise-induced asthma, colleagues assisted with carrying heavy objects (quote 2) or piles of files (quote $3)$. One participant reported to benefit from the fact that his colleagues notified him in case a disinfectant triggering his asthma symptoms had been sprayed in certain locations at the workplace (quote 6). Others considered an own office as helpful, for example, to avoid conflicts concerning whether or not to open office windows, which implies pollen exposure (quote 5).

Quote 5: The allergens, they start about April, May; when colleagues want to let some air in then, I say: "No, I do not want that, because then, the pollen comes in, and it does me no good". Naturally, I do not have this problem in my own office.

To some, technical support was available, for example, in terms of forklifts or lifting carriages to avoid exercise-triggered symptoms (quote 7). Besides the fact that some triggers, above all dust (quote 8 ), simply could not be avoided, trigger avoidance was reported to be limited by certain working conditions. A lot of employees with asthma stated high stress levels at work, which was perceived as contributive to asthma symptoms by some participants (quote 9). Time pressure, a high workload and/or emotionally challenging situations at work, for example, caring for critically ill persons, were reported as reasons for high stress levels among employees with asthma. For example, one participant explained how time pressure and the related need to move quickly triggered her asthma (quote 10). Moreover, many participants described conflicts or lack of instrumental support as demanding. This included lack of support either by colleagues (who, eg, would not take over a certain task; quote 11), line managers (who, eg, would not accept the colleagues taking over a certain task; quote 12) or the employer (who, eg, did not comply with certain modifications that may help to reduce exposure to triggers; quote 13).

Quote 12: She said, for instance: "Now you have been at the counter all morning, now you can do this and that". Well, she didn't care if one does not feel well. She did not show consideration. The colleagues did, but the store manager did not.

A lot of participants also referred to the fact that low control over the types of tasks and when and how to carry out those tasks was detrimental. In work stress research, this type of working condition is referred to as job decision latitude (JDL) and is considered one of the most important job resources, when present. ${ }^{21}$ In our study, experiencing no or little JDL seemed to be a stressor to many participants that interfered with their asthma SMB (quote 14).

\section{Symptom prevention: others}

In addition to trigger avoidance, our participants stated other means of symptom prevention, such as a healthy lifestyle. On the one hand, physical exercise was much appreciated as part of the job by some employees exposed to physical demands (quote 15). On the other hand, physical strain at work, late working hours or shift work was perceived to limit one's ability to engage into exercise in leisure time (eg, in regular gym courses; quote 16). In one case, irregular working hours, for example, in case of business trips and/or related to jet lag, were felt to interfere with control medication intake as another means of symptom prevention (quote 17).

\section{Symptom monitoring}

Use of peak-flow metres at work was considered irrelevant by most participants, because the majority stated that they simply did not use that device or that they monitored their peak expiratory flow only irregularly. Only one participant reported to have a peak-flow metre in the office. Routine medical check-ups with a physician were considered as a means of monitoring by most of the participants (rather than as a means of symptom prevention, as postulated by Mammen and Rhe $\left.^{10}\right)$. Working time regulations seemed to affect this particular SMB: some employees were exempted from work to be able to attend check-ups, but the majority had to make up for the lost hours (quote 18) or had to consult their doctor in their leisure time (quote 19). Enjoyment of and commitment to work were perceived to reduce the likelihood to attend routine medical check-ups for asthma, because people described their jobs as too enjoyable to leave behind for a doctor's visit (quote 20).

Quote 20: I very rarely go to the doctor because I enjoy my job. And for me not to go [to work], it takes an extremely long time.

\section{Acute symptom management: general SMBs}

As the domain of acute symptom management delivered a lot of findings, we decided to split it up in 
'general SMBs', such as the general coping with the disease, and 'specific SMBs', which comprise the reaction to a certain symptom. In case of acute asthma symptoms at work, some employees were allowed to leave earlier (quote 21) or stayed at home (quote 22). One participant criticised that according to his perception, workability is considered as a dichotomous state in the German healthcare system (quote 23). Owing to this subjective flaw in the system, he explained, daily tasks could not be adapted to his actual abilities, and he had to obtain a sick note even if he felt able to perform at least some of his daily tasks.

Quote 23: There are exactly two operating states, namely able to work and unable to work. And sometimes I think: Okay, if it is only an office day with [task B] and so on, then I can cope well. When it is a [task A]-day, it will not work. And then I am forced to get a sick note although I could have gone to work.

Another important point to some was that asthma is a condition that is not overtly noticeable by others. One participant uttered a certain pressure to 'prove' that she is ill despite not looking like it (quote 24). Another participant related this to the assumption that his colleagues suspected that he might not even be ill while staying at home with a sick note. Further, he stated that his asthma seemed to be considered as a hindrance to adequately performing his daily tasks. In his point of view, any questions about his well-being only served the purpose to find out what he would be able to do on the given workday (quote 25). Once again, JDL concerning tasks and working hours and the respective regulations seem to play a crucial role for efficient asthma SMB, also in terms of acute symptom management. A few participants perceived their enjoyment of work as a beneficial factor: the mental stress caused by allergic symptoms due to trigger exposure (eg, physical demands or pollens) was perceived as less impairing when work was enjoyable (quote 26). Some employees, especially those working in a clinical setting, appreciated that medical staff and equipment were around when they had acute asthma problems (quote 27). Others felt comforted when colleagues showed interest in their well-being or offered assistance (quote 28). The physical display of asthma symptoms (eg, coughing or wheezing) or asthma SMB (eg, breathing techniques or using the rescue medication inhaler) was considered a stressor by some employees, especially among those working with clients (quote 29). Participants expressed the concern that any persistent coughing may be interpreted by colleagues or clients as a sign that they suffer from an acute and transmittable disease (quote 30). Generally, several participants described the need to be considered as functioning and healthy, and that they, therefore, concealed their asthma symptoms or SMBs (quote 31 ).
Quote 31: Well, at work, I avoid making things public. Too many questions. Weakness? No idea. I want to be considered as healthy.

\section{Acute symptom management: specific SMBs}

The experience and severity of acute asthma symptoms vary between patients. This results in a range of strategies to cope with them. When suffering from acute asthma symptoms, a lot of our participants subjectively benefited from taking deep breaths of fresh air, an SMB easily implemented by some (quote 32), but more troublesome for others who-in rare cases-had to violate safety rules at work to ensure the preferred ventilation in their rooms (quote 33). The inhalation of reliever medication was also an important SMB to the participants (quote 34), in single cases, such use was promoted by colleagues, for instance, by those coworkers who suffered from a chronic condition themselves (quote 35). Others benefited from an own office so that the rescue medication inhaler could be used in privacy (quote 36 ).

Quote 35: When there is a situation-we have to go down to the training room, and it happens that I forgot my spray-, then my colleague says immediately: "Do you have your spray with you?" She reminds me of it. But I do the same for her. She has another illness. And I also always watch out that everything is alright.

Some participants experienced difficulties in taking their reliever medication. One employee had to suffer from acute symptoms as she was unable to leave the workplace (quote 37). Other participants went to restrooms to take their reliever medication and to avoid questions and pity by others (quote 38). Another means of acute asthma SMB was taking a break or slowing down at work (quote 39). Again, coworkers assisted with the implementation of this SMB, for example, by reminding the affected person to take a break (quote 40). One participant described how other chronically ill colleagues, especially young ones, coped with their conditions and how their behaviour led to an organisational change in dealing with chronic as well as acute illness (quote 41). The above-mentioned JDL enables participants to take breaks to attend to acute asthma symptoms (quote 32). One participant spoke of bureaucratic difficulties in taking breaks as needed, because she had to notify her line manager whenever she left the workplace (quote 42). Further, time pressure was reported to interfere with the opportunity to take breaks (quote 43), and staff shortage was another problem impeding acute asthma SMBs (quote 37).

Quote 43: I often was in that lab all day long. I hardly got out of there. Yes, and that was difficult. And when I needed my spray, I went into the corner; I sometimes did that, or opened a window. At work, it was difficult. I cannot simply say: "Well, I need to get some fresh air right now" or so. That wasn't an option. The stuff 
has to get done, as I said, there is a time window, and yeah, that was difficult.

Additional SMBs to cope with acute symptoms were breathing techniques, taking a certain body position or emotionally calming oneself down (quote 44). The implementation was reported to be quite easy and not connected to certain supportive or impeding factors. One further acute SMB was mentioned by many workers with asthma: they left the present setting when experiencing asthma symptoms. Two reasons could be found for this SMB: first, it was done to socially withdraw from others and to be left alone, for example, to avoid questions or pity (quote 38 ) or to get some quiet (quote 45). Second, the retreat had the purpose to avoid triggers which caused the symptoms in the situation (quote 46). Some employees described their colleagues or line managers as very understanding concerning their withdrawal (quote 47). Others suffered from the fact that a suitable refuge was lacking (quote 48).

\section{Communication}

A lot of the participants stated that they talked about their condition at work more often to colleagues than to line managers. The reported motives for self-disclosure differed: colleagues mostly seemed to be informed deliberately (quote 49) or because they noticed the symptoms or the applied SMBs (quote 50). Line managers or employers, by contrast, often appeared to be informed because of the planned inpatient rehabilitation (quote 51 ) and the need to arrange the respective dates, but also deliberately (quote 52).

Quote 52: I think that is very important, yes. The more openly you communicate it, the more naturally you deal with it and adjust to it, I think, the easier it is also for them, does not matter for whom, the counterpart, whether it be friends, family or in this case the employer. I do not make a distinction if it is a boss or simply a colleague.

One distinct motive for employees with asthma to tell others about their condition was the described need to prepare them for emergency situations (quote 53). Acceptance by a stable social environment seemed to be of importance to implement asthma SMB corporately (quote 54), and self-disclosure in combination with display of SMB in front of others was considered as helpful by one participant to be left alone in case of asthma symptoms (quote 55). Reported reasons for limited self-disclosure mainly were fear of job loss (quote 56) and reluctance to talk about asthma (quote 25). One participant who stated to feel ashamed of his asthma (quote 57) described the disadvantages of keeping his condition a secret (quote 58).

Quote 58: Sure, naturally you have a disadvantage. I mean, people who are cool about it from the beginning have a much more unburdened life.

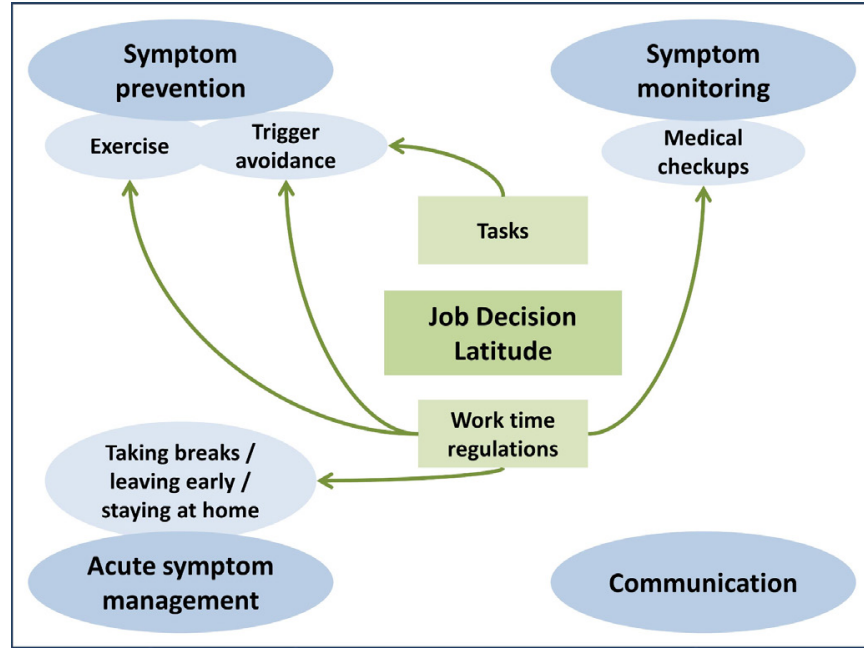

Figure $1 \mathrm{JDL}$ as a determinant for asthma SMB at work: all relationships were positive (eg, the higher JDL concerning tasks, the better symptom prevention was perceived). JDL, job decision latitude; SMB, selfmanagement behaviour.

\section{DISCUSSION}

\section{Main findings}

The most influential factors appeared to be elements of well-established psychological stress models, above all subjective JDL and experienced social support (for an overview, see references ${ }^{22-24}$ ). Our findings are summarised in figures 1-3.

Figure 1 shows the effect of perceived JDL on specific SMBs. These include the domains symptom prevention, symptom monitoring and acute symptom management. Reported JDL did not seem to affect the communication domain though. One's control over when and how things

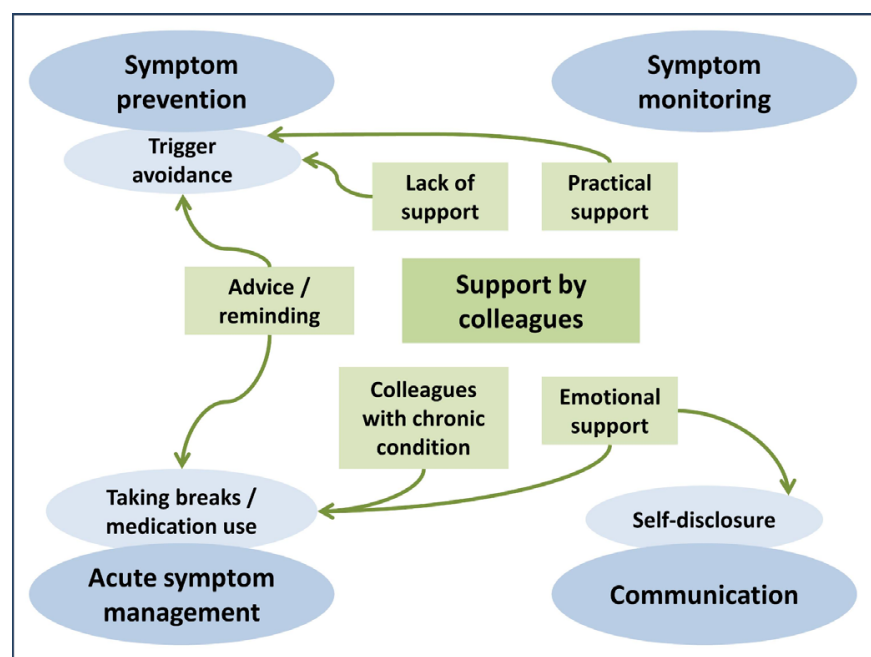

Figure 2 Support by colleagues as a determinant for asthma SMB at work: all relationships were positive (eg, the higher the perceived emotional support, the more likely selfdisclosure was implemented), the only exception was lack of support (ie, with increasing perceptions of lacking support, opportunities for trigger avoidance were perceived as more restricted). SMB, self-management behaviour. 


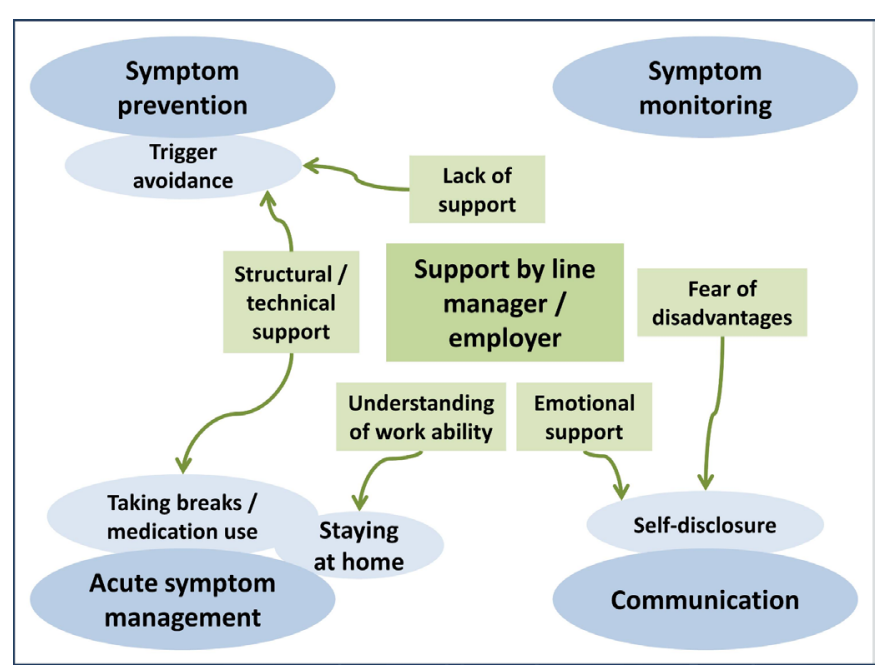

Figure 3 Support by line managers and employer as a determinant for asthma SMB at work: all relationships were positive (eg, the higher the structural support was, the more acute symptom management was perceived to be possible); the only exception was lack of support (ie, the higher the lack of support, the less trigger avoidance was possible) and fear of disadvantages (ie, the more fear was perceived to be associated with less self-disclosure). SMB, self-management behaviour.

were done at work seemed to have greater impact on asthma SMB than the control over the tasks themselves.

As depicted in figure 2, support by colleagues was considered to exert effects on symptom prevention, acute symptom management and self-disclosure. Practical support and lack of support were subjectively related to trigger avoidance, advice and reminding by colleagues to trigger avoidance and the themes 'taking breaks' and 'medication use'. The latter were also reported to be influenced by the fact whether colleagues themselves suffered from a chronic condition as well as emotional support, which promoted self-disclosure, too. Symptom monitoring was not reported to be affected by any type of support, neither by colleagues nor by line managers or employers (see figure 3).

Subjective lack of line manager support was considered to interfere with trigger avoidance. Technical and structural support (eg, an own office) helped to avoid triggers and to take breaks and/or medication. The understanding of workability as a dichotomous state and the concerning rules implemented by the employer influenced the employee's decision whether to stay at home with a sick note or not. Self-disclosure was contingent on perceived emotional support by line managers, whereas fear of disadvantages was felt to result in limited self-disclosure.

\section{Findings in relation to other studies}

Support by colleagues and line managers is strongly interrelated with self-disclosure of asthma at work, as the results of other studies, qualitative and quantitative alike, show. ${ }^{11} 12$ Notably though, self-disclosure seems to be a prerequisite to receive the above-mentioned types of support. For instance, coworkers may be less inclined to take over a certain asthma-triggering task if they do not know about their colleague's asthma. Zhao $e t a l^{11}$ reported similar evidence showing that employees with asthma disclosed their condition to colleagues hoping that their coworkers would offer them more understanding and support. However, not only the mere self-disclosure itself but also the addressee is of importance: in this respect, our observations confirmed another finding by Zhao et $a l^{11}$ who stated that, generally, employees with asthma disclosed their condition more frequently to colleagues than to line managers. The reasons for limited self-disclosure ranged from feeling ashamed to fear of job loss. Some of our participants tended to hide their asthma symptoms and SMBs out of their need to appear functional and healthy. This is also in keeping with the evidence by Zhao et $a l^{11}$ who found that limited privacy at the workplace impaired acute asthma symptom management at work, for example, medication use. The reasons were reported to be self-consciousness, embarrassment and inconvenience. ${ }^{11}$ A link to support was also reported: when social support was lacking, employees experiencing asthma symptoms responded more quickly to them. ${ }^{11}$ One reason for this behaviour may be the need to prevent that asthma symptoms aggravate and become socially noticeable.

Our findings concerning limited self-disclosure relate to the topic of stigma, even though none of our participants used this specific term. The following thoughts are the authors' interpretation of the findings. Goffman, ${ }^{25}$ who coined that concept, related stigma to 'a failing, a shortcoming, a handicap'. Our participants described it as a need to function or to appear healthy, which resulted in avoidance of medication use in public or withdrawing from colleagues or clients in case of asthma symptoms, for instance. According to a review concerning stigma and non-communicable respiratory diseases conducted by Rose $e t a l,{ }^{26}$ perceived stigma was related to dyspnoea and cough symptoms, poorer health status and absenteeism in case of asthma (and COPD, combined). This also relates to our findings: in case of asthma, the condition itself is not noticeable, only by its symptoms, such as coughing, or by the applied SMBs, such as using the rescue medication inhaler. Employees with asthma who expect stigmatisation by their colleagues or line managers are likely more inclined to hide their illness and to avoid displaying symptoms or SMBs. As a result, it seems plausible that fear of stigmatisation impairs the implementation of asthma SMBs at work. This could happen directly, for example, when an employee with acute asthma problems does not take their rescue medication, or indirectly, for example, mediated by the above-mentioned interrelation of support and asthma SMB.

Some of our findings overlap with the results of other studies concerning SMB of other diseases than asthma. For instance, the relation between working hours and attending regular check-ups was also found among individuals with chronic kidney disease ${ }^{27}$ or diabetes. ${ }^{12}$ Employees with diabetes also reported that their medication use was 
contingent on the availability of a private room other than restrooms at work. ${ }^{12}$ This illustrates that some SMBs and influencing working conditions seem to be important to patients across different types of conditions. By contrast, some other behaviours as well as the influential working conditions are likely asthma-specific, for example, trigger avoidance. Such disease specificity needs to be examined in greater detail in future research.

\section{Strengths and weaknesses of the study}

The main strengths of this study are that patients with asthma, but free of comorbid COPD were included, that diagnoses were verified by physicians and that participants were recruited in two rehabilitation clinics to reduce potential HWEs. Furthermore, our study was based on a conceptual framework ${ }^{10}$ which shaped the development of the topic guide and our initial coding system. Moreover, transcripts were coded by three analysts.

Some limitations of our qualitative interview study need to be mentioned.

\section{Concept of asthma SMB}

This study adopted a specific focus on asthma-related $\mathrm{SMB}$, and we, therefore, did not draw on broader concepts of chronic disease management. For instance, the concept by Lorig and Holman ${ }^{28}$ comprises medical or behavioural management, role management and emotional management. The latter includes aspects we did not refer to in our topic guide. Nevertheless, one could argue that aspects of role management could be found in the domains 'prevention' and 'communication' by Mammen and Rhee, ${ }^{10}$ whose concepts guided the present study.

\section{Recruitment strategy}

We recruited study participants in rehabilitation clinics based on the assumption that we would thereby include patients with rather severe asthma whose workability is at stake or already impaired. By doing so, we attempted to reduce potential HWEs. We cannot rule out however that our specific study setting might be associated with additional selection processes. For instance, our study participants had apparently been able to overcome bureaucratic challenges associated with the admission to rehabilitation clinics. This may signal that they are particularly well-organised, health literate and may thus display fairly good asthma SMB. Furthermore, the fact that our participants decided to enter inpatient rehabilitation implies that they implicitly prioritised their asthma as compared with their work demands (at least for a limited period of time), which may point to particularly beneficial attitudes towards SMB at work. Moreover, patients in rehabilitation gain a lot of (additional) knowledge and skills concerning their condition and symptoms. We cannot rule out that these recently acquired skills and improved health literacy influenced the participants' responses concerning implemented SMBs.
Sample

Most of our participants worked in white-collar jobs (or comparable). Additional themes might have emerged if the sample had included workers in other professions. We cannot rule out that participation was related to the topic of our study (eg, either those with little difficulties or those with severe difficulties regarding asthma SMB at work may have participated), and that this has affected the range of themes that emerged from our data.

\section{Mode of interviewing}

In qualitative research, the question must be discussed if telephone interviews deliver the same data quality than face-to-face interviews. In earlier studies, comparability of interviews conducted face-to-face or by telephone has been reported. ${ }^{29}$ Our reasons for an interview by phone were mainly organisational ones, for example, the respective patients did not have any time for a faceto-face interview in the clinic before their discharge. Telephone interviews and face-to-face interviews did not differ regarding their length (average duration: $34 \mathrm{~min}$ in both groups) or informative value (average number of codes: 73 in face-to-face interviews and 67 in telephone interviews; total range: from 28 to 110).

\section{Data analysis}

The topic guide and the code system were initially based on the four asthma SMB domains suggested by Mammen and Rhee. ${ }^{10}$ We cannot rule out that this approach has to some extent narrowed the analysts' perspective while establishing the code system, for example, concerning the scope and quantity of main categories. Further, patients were not involved in data analyses, and neither did we approach patients with potential follow-up questions for clarification during the analytical process. Moreover, the three members of our interdisciplinary study team involved in data analysis have similar professional backgrounds, such as psychology, social work and public health. A more diverse professional background of the study team members could have led to other results.

\section{Conclusions and future research}

This qualitative interview study indicated that participants regarded their experienced levels of JDL and social support by colleagues and line managers to influence their asthma SMB at work. If our findings are supported by future quantitative evidence, a range of interventions is conceivable, for instance, supplementation of patient education programmes in pulmonary rehabilitation clinics for patients with asthma who return to work after their treatment (eg, addressing self-disclosure and support at the workplace). Further, interventions may be implemented in companies with a focus on the importance of JDL and support for chronically ill employees.

Future research should aim to deliver statistical evidence for the relationships we found between working conditions and asthma SMBs. Further outcomes, such as actually implemented asthma SMB, asthma morbidity 
and the prognosis of workability, need to be investigated in quantitative studies.

Acknowledgements The authors want to thank all the individuals who participated in our study.

Contributors KH: acquisition, analysis and interpretation of data; drafting and revising the work critically for important intellectual content; final approval of the version to be published and agreement to be accountable for all aspects of the work. PV-E: analysis and interpretation of data; revising the work critically for important intellectual content; final approval of the version to be published and agreement to be accountable for all aspects of the work. SH and JG: acquisition and interpretation of data; revising the work critically for important intellectual content; final approval of the version to be published and agreement to be accountable for all aspects of the work. AL: conception, design, acquisition, analysis and interpretation of data; drafting and revising the work critically for important intellectual content; final approval of the version to be published and agreement to be accountable for all aspects of the work.

Funding This work was supported by refonet-Rehabilitation Research Network of the German Pension Fund Rhineland (grant no 14006).

Competing interests None declared.

Patient consent Obtained.

Ethics approval Institutional Review Board of the Medical Faculty of the HeinrichHeine University of Düsseldorf (no 5764R).

Provenance and peer review Not commissioned; externally peer reviewed.

Data sharing statement All transcripts of interviews are available in German. Data are provided for secondary analysis on request to the corresponding author. Prerequisites are that a research protocol is submitted and approved. Apart from the transcripts, no additional data are available.

Open access This is an open access article distributed in accordance with the Creative Commons Attribution Non Commercial (CC BY-NC 4.0) license, which permits others to distribute, remix, adapt, build upon this work non-commercially, and license their derivative works on different terms, provided the original work is properly cited, appropriate credit is given, any changes made indicated, and the use is non-commercial. See: http://creativecommons.org/licenses/by-nc/4.0/.

\section{REFERENCES}

1. The global asthma report 2014. Auckland, New Zealand: Global Asthma Network, 2014. (cited 2 Feb 2018).

2. Global Initiative for Asthma. Pocket Guide for asthma management and prevention (updated 2017). 2017. http://ginasthma.org/2017pocket-guide-for-asthma-management-and-prevention/ (cited $2 \mathrm{Feb}$ 2018).

3. Pawankar R. Allergic diseases and asthma: a global public health concern and a call to action. World Allergy Organ J 2014;7:1-3.

4. Aumann I, Prenzler A, Welte T, et al. [Epidemiology and costs of asthma in Germany - a systematic literature review]. Pneumologie 2014;68:557-67.

5. Loerbroks A, Bosch JA, Sheikh A, et al. Reports of wheezing and of diagnosed asthma are associated with impaired social functioning: Secondary analysis of the cross-sectional World Health Survey data. J Psychosom Res 2018;105:52-7.

6. Loerbroks A, Herr RM, Subramanian S, et al. The association of asthma and wheezing with major depressive episodes: an analysis of 245727 women and men from 57 countries. Int J Epidemiol 2012;41:1436-44.

7. Nurmagambetov T, Khavjou O, Murphy L, et al. State-level medical and absenteeism cost of asthma in the United States. J Asthma 2017;54:1-14

8. Schramm B, Ehlken B, Smala A, et al. Cost of illness of atopic asthma and seasonal allergic rhinitis in Germany: 1-yr retrospective study. Eur Respir J 2003;21:116-22.

9. Kotses H, Creer T. Asthma self-management. In: Harver A, Kotses $\mathrm{H}$, eds. Asthma, health and society. New York: Springer, 2010:117-39.

10. Mammen J, Rhee $\mathrm{H}$. Adolescent asthma self-management: a concept analysis and operational definition. Pediatr Allergy Immunol Pulmonol 2012;25:180-9.

11. Zhao DH, Cheung JMY, Smith $L$, et al. Exploring asthma in the workplace: A triangulation of perspectives from management, employees and people with asthma. J Asthma 2017:9:1-9.

12. Heinrichs K, Angerer P, Loerbroks A. Psychosocial working conditions as determinants of asthma self-management at work: $A$ systematic review. J Asthma. In Press.

13. Boot CR, van Exel NJ, van der Gulden JW. "My lung disease won't go away, it's there to stay": profiles of adaptation to functional limitations in workers with asthma and COPD. J Occup Rehabil 2009;19:284-92.

14. Dumas O, Le Moual N, Siroux V, et al. Work related asthma. A causal analysis controlling the healthy worker effect. Occup Environ Med 2013;70:603-10.

15. Pearce N, Checkoway H, Kriebel D. Bias in occupational epidemiology studies. Occup Environ Med 2007;64:562-8.

16. Lindström I, Pallasaho P, Luukkonen R, et al. Reduced work ability in middle-aged men with asthma from youth--a 20-year follow-up. Respir Med 2011;105:950-5.

17. Thaon I, Wild P, Mouchot L, et al. Long-term occupational consequences of asthma in a large French cohort of male workers followed up for 5 years. Am J Ind Med 2008;51:317-23.

18. Tinkelman DG, Price DB, Nordyke RJ, et al. Misdiagnosis of COPD and asthma in primary care patients 40 years of age and over. $J$ Asthma 2006;43:75-80.

19. Loerbroks A, Nguyen XQ, Vu-Eickmann P, et al. Psychosocial working conditions and diabetes self-management at work: A qualitative study. Diabetes Res Clin Pract 2018;140:129-38.

20. Mayring P. Qualitative content analysis [Qualitative Inhaltsanalyse]. Weinheim: Beltz, 2010

21. Karasek RA. Job Demands, Job Decision Latitude, and Mental Strain: Implications for Job Redesign. Adm Sci Q 1979;24:285-308.

22. Häusser JA, Mojzisch A, Niesel M, et al. Ten years on: A review of recent research on the Job Demand-Control (-Support) model and psychological well-being. Work Stress 2010;24:1-35.

23. de Lange AH, Taris TW, Kompier MA, et al. "The very best of the millennium": longitudinal research and the demand-control-(support) model. J Occup Health Psychol 2003;8:282-305.

24. Van der Doef M, Maes S. The Job Demand-Control (-Support) Model and psychological well-being: a review of 20 years of empirical research. Work Stress 1999;13:87-114.

25. Goffman E. Stigma: notes on the management of spoiled identity. New York, NY: Simon \& Schuster, 1963.

26. Rose S, Paul C, Boyes A, et al. Stigma-related experiences in noncommunicable respiratory diseases: A systematic review. Chron Respir Dis 2017;14:199-216.

27. McQuoid J, Welsh J, Strazdins L, et al. Integrating paid work and chronic illness in daily life: A space-time approach to understanding the challenges. Health Place 2015;34:83-91.

28. Lorig KR, Holman H. Self-management education: history, definition, outcomes, and mechanisms. Ann Behav Med 2003;26:1-7.

29. Sturges JE, Hanrahan KJ. Comparing telephone and face-to-face qualitative interviewing: a research note. Qualitative Research 2004;4:107-18. 